\title{
SEQUENCE OF STUDENTS' ACTIVITIES IN TELLING TIME IN ENGLISH TEXTBOOK ENTITLED "WHEN ENGLISH RINGS A BELL"
}

\author{
Sovicana Liontine Sinaga ${ }^{1}$, Chris Yovie Sitorus ${ }^{2}$, Rani Yanti Sihotang ${ }^{3}$,Erikson Saragih ${ }^{4}$ \\ Universitas Prima Indonesia \\ ${ }^{1}$ liontinsinaga@gmail.com, ${ }^{2}$ krisyopi27@gmail.com, ${ }^{3}$ ranysihotang4@ gmail.com, \\ ${ }^{4}$ erikson.saragih@gmail.com
}

\begin{abstract}
The study aims to analyze the various sequences of students' activities in telling time. The book "When English Rings a Bell" is a book that researchers choose to specialize in research on time because time is the most important aspect for students to know in each activity. In analyzing data, researchers guide the (Bogdan \& Biklen, 1997) descriptive methods of qualitative research as one of the procedures that produce descriptive data of the speech or written and attitudes of the observed ones. The researchers were also suggested in this study that children first read time and then soon after record time. The results of this study showed that by using this book students can sequence activities in telling time. Hour, halfhour, quarter-hour, five minute, and minute times in the sequence. And the teachers can teach students who have difficulty reading and recording analog and digital clocks.
\end{abstract}

Keywords: Analyze, Activities, Telling a Time

\section{INTRODUCTION}

Some of the problems in the seventh-grade English book entitled "When English Rings a Bell" are the lack of media that students use in learning about student material for telling time. The activity in the book is to listen to the teacher, repeating one teacher's words. Notifying daily mealtimes, forming groups, telling activities on Sundays and holidays, and making conversations in English. The study needs to be done because there is still a great deal of student difficulty in relating the sequence of students' activities at the time. In addition to time, the period of activities is every other factor that tells the children. Almost every elegance is to be had hours so that sooner or later students ought to discover ways to rely upon themselves to proportion time (Brown, 2005)

This paper is well-thought-out as follows. After the introduction, the next section presents related literature about the definition of time and telling the time. In the Indonesian Dictionary, there are at least 7 items that become the meaning of the word time: (1) the whole series of moments during the process; action or state of being or taking place, (2) duration (moment certain), (3) a certain time to do something, (4) opportunity, tempo, opportunity; (5) when, when; (6) the day (state of the day) and (7) at which time determined based on the division of the globe. That understanding and knowledge can be information for teachers to give students opportunities to show what they know in various ways. (Schwartz et al., 2011),

From birth to death, everything has its time. All that remains is a man who pursues time or time after man. Because if humans don't use their time well, everything will pass. In history, a brief event has consequences that affect age and affect time on a short time scale. Every human has 
a culture that has been linked to material objects. In the lives of children, it is necessary to be able to tell properly what time is it? When kids first go to school they're always curious about time. Students always ask the teacher what time of rest? What time is lunch? What time after school? These days digital clocks have been more widely used because they are so easily known that some students may think that they no longer need to know analog clocks. The clock should be included temporarily to notify the learning process that takes place. Using factual or background information from both home and informal teaching (Partington et al., 1979). The words clock and o'clock each has its meaning, which is different from one another. It's just that, often the use of language is not very accurate in using the two words, each of which is often used with the same meaning (Gordon, 1998).

According to (Sherman, 1996) The word clock denotes the meaning of 'time or period', while the word clock implies 'moment or time'. Thus, if the meaning to be expressed is 'time or moment', the correct word to use is hit, as in the following example. The meeting will start at 10:00 am On the other hand, if what you want to say is 'period' or 'period', the correct word to use is hours, as in the following example sentence. We work eight hours a day. Apart from being used to denote the meaning of 'time' or a period, the word clock also means 'a a timepiece' or 'watch', as in the words for a wall clock or a watch. This type of information is very valuable to teachers who want to develop a more holistic image of students in the class and who understand the importance of making connections between home and school studies. (Tomlinson \& Masuhara, 2017).

\section{Telling The Time}

According to (Moyer, 1988) students learn to know time through class activities and playgrounds that involve the use of time face-time of cement stones built on the school playground. Telling a hard time to learn because of the number of skills that need to be acquired, for example, determining a time for hours, minutes, a quarter of an hour, and minutes before the hour.

Traditionally the concept of teaching time, difficult for students to understand, drawing hours telling stories about pictures can shape connections that make timeless abstract and more personal. It can also reveal new insights about how a child understands what it takes to tell time. An obsession with the role and the hand movements of the clock is one aspect of counting time that appears in many images. Quoted in (Clarke, 1998) with actual development insight, but it may be a promising way to travel through time. There are three phases of a strategy used to teach students to know the time. These are (1) learning to express minutes,(2) another way to express time after hours, and (3) learning to express minutes before hours. This is a good way to build skills so students don't feel overwhelmed by material (Wieber et al., 2017). Several researchers have a focus on teaching an individual with disabilities to tell time using an analog o'clock (Horn et al., 2006)

\section{METHOD}

The study uses qualitative descriptive methods. According to boghdan \& biklen (1975), which means qualitative research is one of the procedures that produce descriptive data of the speech or written and attitudes of the people observed. In research, there are several research approaches used in research design. Descriptive design research is used to help describe answers with existing questions such as What, Who, When, Where, and How are related to the research problem. researchers used observed objects in the environment and analyzed the data in detail which led to important recommendations. The descriptive design also often uses 
observational methods whose results cannot be replicated and serve for instrument-dependent measurements and observations. The object of this research is the seventh grade English textbook entitled "When English Rings Bell" and this research plan has been implemented in November.

\section{RESULTS AND DISCUSSION}

\section{Results}

The author analyzes that the use of time in the book When English Rings a Bell consists of O'clock, Quarter, Quarter To, Half Past. The following are Time Spent, Clock Number, and How to Read:

Table 1. The Use of Time Students Spend Reading The Clock

\begin{tabular}{lll}
\hline Time Spent & Clock Number & How To Read \\
\hline O'clock & $12: 00$ & Twelve O'clock \\
Quarter & $3: 15$ & Quarter Past Three \\
Quarter To & $9: 45$ & Quarter To Ten \\
\hline Half Past & $6: 30$ & Half Past Six \\
\hline
\end{tabular}

\section{Discussion}

In this study the authors found in the seventh grade English textbook titled "When English Rings a Bell" in Chapter III on page 37 under the title What Time Is It? Invite students to learn about the clock and how to tell the time in each activity (Wachida, 2014). The first book tells what students must do by listening to the teacher first. The teacher would ask "What Time Is It?" And then students answer the teacher's questions together and so on. It also tells the student to repeat the words spoken by his or her teacher one by one. Say the sentence loud and clear.

Here the writers will give an analytical view, the book should first show a clock that shows the $12 \mathrm{o}$ 'clock number and then have the students draw a clock on each of their notebooks so that the students will have the clock detailed. On page 39, the book gives an idea at which time Beni would eat his daily meal verbally. The book also describes the empty hour at which Beni eats each day from breakfast, lunch, and dinner. Then the student was told to fill out the blank clock according to just what time Beni ate. The writer analyzed the beauty of this book on page 39 as showing the time for Beni. It designs well so that students can readily understand and remember because the activity in time is often carried out.

On page 40 of this book tells students to form a group. Because on the previous page benny had already told him what time he was eating. Now the student will repeat the already existing example. This page also tells students to make a chart of students' mealtimes such as breakfast, lunch, and dinner that is started with the student's name so that another friend can look at a classmate's meal. Then the students will write their hands on the notebook according to each student's mealtime. After that, each student was told to tell the student's mealtimes from breakfast to dinner in the group in front of the class orally. The writer analyzed on page 40 that the book enabled the student to understand because it enabled the student to understand both 
orally and in writing. The book designed a table that contained students' mealtimes and poured it into short stories.

On page 40 of this book, Edo will describe his Sunday activities. The book instructs students to draw a clock indicating Edo's activity begins to wake up until it finishes playing. Edo wakes up and washes at $7 \mathrm{am}$, then at 8:00 A.m., Udin, Beni, and another fellow kites. The last time they went to the library, it was their hobby. On this page, students are asked to listen and repeat the teacher reading Edo activities. Then described the blank clock according to the reading text in the book. The author analyzed that this page should merely provide an example and then asked students to make appropriate activities in their own time. To help students better understand what is meant by this page 41 .

On page 42 is a continuation of Edo activity. At half-past four in the afternoon Edo and his family went to the park on a bike. At 7:00 a.m., he had dinner together. His father made a delicious chicken roast. At 9:00 Edo fell asleep and his father said good night and kissed him. At half-past nine Edo prays before bedtime. The writers analyzed that what was written in this book was less interesting because not all the students knew how to place a clock with the text on the side. Many students are unfamiliar with this page Because students don't quite understand the difference between half, past, quarter to, and quarter past.

On page 43 students were simply asked to write information on Edo's already completed activity according to the specified time in the form of the chart. The author's analysis on this page is good, but after setting up a chart of Edo activities it is still better to ask students to resume students' activities in their own time. Page 44 of this book tells students to listen carefully to the teacher's conversation and then repeat the conversation one sentence at a time after the teacher. Then formed a group to play the role of the speaker in the conversation.

On page 45 students were only asked to write down the conversation already made. The writer's analysis on this page makes for role-playing because it does not bore students with mediocre techniques. Role-playing also renews the classroom atmosphere. On page 46 this tells students of classmates' daily activities and daily activities in the form of a chart. Then students look for mates because in this activity it will work in pairs. The last student will interview each other to find out what activities his classmates are doing every day and the student will put the information on the table. On page 46 this highly appreciative writer has well-designed the sequence of students' activities in telling time.

\section{CONCLUSION}

The conclusion from the study is that the sequence of students' activities in telling that time needs to be increased again because the strategy used by the book "When English Rings a Bell" Rings a Bell "is to help teachers know the progress of students in understanding about time and how the student read analog and digital clocks in English. Teachers need to develop strategies to require students to be able to understand the clock and identify the stages of development concerning understanding the children's perceptions of the clock.

This study proved evidence of a more advanced understanding of the nature of the clock, providing more information and insight into the factors that influence its learning. And additional knowledge of the clock. The researchers hope that this research is very useful and can help future researchers to deepen the theory of time and be able to think critically about time analysis. The researchers hope that this research is very useful and can help future 
researchers to deepen the theory of time and be able to think critically about telling the time analysis.

\section{ACKNOWLEDGMENTS}

Praise and thanksgiving to God Almighty who has given grace and health so that the author can complete this research well. This research is a requirement to complete the SEMINAR AND PUBLICATION course assignments, English Language and Literature Study Program, Faculty of Teacher Training and Education, Prima Indonesia University. With research entitled "Sequence of Students' Activities in Telling Time in English Textbook entitled "When English Rings a Bell". On this occasion, the author received a lot of help and guidance from various parties. Therefore, the authors would like to thank:

1. Dr. Erikson Saragih, S.Pd., M.Hum. Lecturers of SEMINAR AND PUBLICATION course who are willing to provide motivation and guidance to the author so that this research can be completed.

2. Yenita Br Sembiring, S.S., M.Hum. Head of the English Language and Literature study program who has been willing to provide motivation and guidance to the author so that this research can be completed.

3. Especially to our beloved parents and our brothers, sisters, and brothers who are always patient and loyal to give encouragement, motivation, and prayer to us starting from the lecture process and until the assignment this end.

\section{REFERENCES}

Bogdan, R., \& Biklen, S. K. (1997). Qualitative research for education. Allyn \& Bacon Boston, MA.

Brown, S. (2005). Assessment for learning. Learning and Teaching in Higher Education, 1, 81-89.

Clarke, D. (1998). children's understanding of the clock in the digital age. Primary Educator, 9-12.

Gordon, S. P. (1998). Stuart Sherman. Telling Time: Clocks, Diaries, and English Diurnal Form, 1660-1785. Chicago: University of Chicago Press. 1997. Pp. xvi, 323. \$60.00. ISBN 0-226-75276-3. Albion, 30(1), 120-122. https://doi.org/10.2307/4052414

Horn, C., Schuster, J. W., \& Collins, B. C. (2006). Use of response cards to teach telling time to students with moderate and severe disabilities. Education and Training in Developmental Disabilities, 382-391.

Moyer, M. . (1988). Let's teach time-using as well as time-telling. Academic Therapy, 453-456.

Partington, J. W., Sundberg, M. L., Iwata, B. A., \& Mountjoy, P. T. (1979). A task-analysis approach to time telling instruction for normal and educable mentally impaired children. Education and Treatment of Children, 17-29.

Schwartz, D. L., Chase, C. C., Oppezzo, M. A., \& Chin, D. B. (2011). Practicing Versus Inventing With Contrasting Cases: The Effects of Telling First on Learning and Transfer. Journal of Educational Psychology, 103(4), 759-775. https://doi.org/10.1037/a0025140

Sherman, S. (1996). Telling time: clocks, diaries, and English diurnal form, 1660-1785. University of Chicago Press.

Tomlinson, B., \& Masuhara, H. (2017). The complete guide to the theory and practice of materials development for language learning. John Wiley \& Sons. 
Wachida, S. \& A. G. (2014). BAHASA INGGRIS “WHEN ENGLISH RINGS A BELL”. Pusat Kurikulum dan Perbukuan, Balitbang, Kemdikbud.

Wieber, A. E., Evoy, K., McLaughlin, T., Kellogg, E., Williams, R. L., Peterson, S. M., \& Rinaldi, L. (2017). The Effects of a Modified Direct Instruction Procedure on Time Telling for a Third Grade Student with Learning Disabilities with a Brief Comparison of Interesting and Boring Formats. Learning Disabilities: A Contemporary Journal, 15(2), 239-248. 